\title{
Impact and internal pressure failure of E-glass and S-glass epoxy composite elbow pipe joints influenced by sea water
}

\begin{abstract}
Consequences of sea water absorption on the impact behaviour of glass/epoxy composite elbow pipe joints were experimentally investigated. Glass-epoxy elbow pipe joints using E-glass and Sglass were fabricated via the hand layup method. The pipe joints were immersed in water as per the current conditions for 0,3 and 6 months. The relation between the unaged and aged samples was studied by calculating the contact force, displacement and absorbed energy values from the impact tests. Therefore, it is concluded that sea water raised the ageing period of both Eglass/epoxy and S-glass/epoxy fibre-reinforced composite elbow pipe joints which resulted in the degradation between the fibre and resin interface and which was prominent in the elbow joints fabricated with E-glass rather than the one's fabricated with the proposed S-glass fibre.
\end{abstract}

Keyword: Natural sea water; Glass/epoxy composite elbow pipe joints; Moisture absorption; Impact behaviour 